\title{
Stable isotopes in barnacles as a tool to understand green sea turtle (Chelonia mydas) regional movement patterns
}

\author{
M. Detjen ${ }^{1}$, E. Sterling ${ }^{1,2}$, and A. Gómez ${ }^{3}$ \\ ${ }^{1}$ Department of Ecology, Evolution \& Environmental Biology, Columbia University, 1200 Amsterdam Avenue, \\ New York, NY 10027, USA \\ ${ }^{2}$ Center for Biodiversity and Conservation, American Museum of Natural History, 200 Central Park West, \\ New York, NY 10024, USA \\ ${ }^{3}$ ICF International, 1725 I St. NW, Washington, DC, 20006, USA \\ Correspondence to: M. Detjen (md2986@caa.columbia.edu)
}

Received: 14 January 2015 - Published in Biogeosciences Discuss.: 23 March 2015

Revised: 18 October 2015 - Accepted: 14 November 2015 - Published: 8 December 2015

\begin{abstract}
Sea turtles are migratory animals that travel long distances between their feeding and breeding grounds. Traditional methods for researching sea turtle migratory behavior have important disadvantages, and the development of alternatives would enhance our ability to monitor and manage these globally endangered species. Here we report on the isotope signatures in green sea-turtle (Chelonia mydas) barnacles (Platylepas sp.) and discuss their potential relevance as tools with which to study green sea turtle migration and habitat use patterns. We analyzed oxygen $\left({ }^{18} \mathrm{O}\right)$ and carbon $\left(\delta^{13} \mathrm{C}\right)$ isotope ratios in barnacle calcite layers from specimens collected from green turtles captured at the Palmyra Atoll National Wildlife Refuge (PANWR) in the central Pacific. Carbon isotopes were not informative in this study. However, the oxygen isotope results suggest likely regional movement patterns when mapped onto a predictive oxygen isotope map of the Pacific. Barnacle proxies could therefore complement other methods in understanding regional movement patterns, informing more effective conservation policy that takes into account connectivity between populations.
\end{abstract}

\section{Introduction}

Long-distance migratory behavior between breeding and feeding grounds, a key component of sea turtle ecology, creates important research and conservation challenges (Godley et al., 2010). Understanding migration and habitat use patterns is a critical step in the design of comprehensive con- servation and management strategies aimed at protecting all of a species' range, including the corridors connecting distant habitats. For many sea turtle populations we lack detailed spatiotemporal knowledge about migration patterns, as well as fine-scale understanding of habitat use. This dearth of information may hinder conservation efforts, especially in scarcely studied areas such as the central Pacific (Wallace et al., 2010).

Previous studies on sea turtle movement patterns have been based on mark and recapture, satellite telemetry, or genetic analysis (Godley et al., 2010). Although these methods have provided key insights, they also have important shortcomings. Mark and recapture can have very low return rates (Oosthuizen et al., 2010). Satellite telemetry is a very effective method for tracking turtles across long distances but can be prohibitively expensive, and loss and malfunction of transmitters is common (Hays et al., 2007; Hebblewhite and Haydon, 2010). Genetic studies can be a very effective way of delineating population structure and natal origin, but are uninformative about movements after the sea turtles hatch (Bowen and Karl, 2007). Therefore, additional methods are needed to help us map patterns of movement and habitat use at scales useful for conservation planning (Godley et al., 2010).

Because of their intimate connections, species that are associates of particular hosts have been used as proxies for the study of host ecology, demography, and evolutionary history (Nieberding and Olivieri, 2007). Recent research has shown that studying associate species such as parasites and 
commensals can be a cost-effective alternative to ecological research on the host themselves (Byers et al., 2011; Hechinger et al., 2007). Several barnacle species are commonly found on sea turtles, attached to the skin and shell. Barnacles are found in the majority of green turtles observed in a long-term study of marine turtles at Palmyra Atoll National Wildlife Refuge (A. Gómez, personal communication, 2012), and they have been reported widely from sea turtle populations from across the world (Casale et al., 2004; Frick et al., 2010; Rawson et al., 2003; Schwartz, 1960; TorresPratts et al., 2009; Zardus and Balazs, 2007). As obligate commensals, these barnacles form close, presumably longlasting associations with their hosts, and may thus provide useful information about turtle ecology.

Previous studies have shown that isotopes in barnacle calcite can be used to reconstruct migratory patterns and habitat use in California gray whales (Killingley, 1980) and loggerhead turtles (Killingley and Lutcavage, 1983). Isotope ratios in calcite layers can be used to approximate the water temperature throughout the life of individual barnacles because warmer waters have reduced oxygen ratios (Killingley and Lutcavage, 1983), where the oxygen isotopes in the barnacle calcite fractionate or change in relative proportion during calcite formation depending on the oxygen ratios in the surrounding water (Kendall and Caldwell, 1998). Therefore, oxygen isotope ratios obtained from barnacles can be informative about turtle movements at large scales, as long as those movements occurred along water temperature gradients (Killingley and Lutcavage, 1983). These movements can be traced by comparing barnacle oxygen isotope ratios to mapped predictions for these values. Temporal reconstruction could potentially also be added as our understanding of the pace at which successive barnacle calcite layers are laid down improves. Carbon isotope ratios can be expected to vary as microhabitats differ in the concentration of dissolved carbon, and can therefore provide information about habitat occupancy across sites, with lagoons and the pelagic zone assumed to have low and high carbon conditions respectively (Killingley and Lutcavage, 1983). Here we report on oxygen $\left(\delta^{18} \mathrm{O}\right)$ and carbon $\left(\delta^{13} \mathrm{C}\right)$ isotopes in the barnacle Platylepas sp., an epibiont of turtles, collected from green sea turtles (Chelonia mydas) at Palmyra Atoll National Wildlife Refuge in the central Pacific and discuss the potential of this method as a tool with which to study sea turtle movements.

\section{Materials and methods}

The barnacle specimens used in the experiment were collected at Palmyra Atoll National Wildlife Refuge (PANWR; $05^{\circ} 52^{\prime} \mathrm{N}, 162^{\circ} 05^{\prime} \mathrm{W}$ ), central Pacific Ocean. The atoll has a wide shallow reef, extensive reef terraces at both the eastern and western ends, and three lagoons (Collen et al., 2009). The islets and 12 nautical miles of the surrounding ocean have been designated a marine protected area by the US Fish and
Wildlife Service since 2001. In 2005, the Center for Biodiversity and Conservation of the American Museum of Natural History initiated a research and conservation program for sea turtles at PANWR. The program includes research into the turtles' distribution and abundance, connectivity, feeding ecology, health, and threats (McFadden et al., 2014; Sterling et al., 2013). The sea turtle population at this site has been studied using mark and recapture, satellite telemetry, and genetic analysis (Sterling et al., 2013).

Platylepas sp. barnacles were collected from adult green sea turtles caught in PANWR during the summer of 2011. These barnacles were found embedded in the turtles' soft tissue (A. Gómez, personal observation, 2011). Barnacles were removed from the turtles' skin and stored in vials with $90 \%$ ethanol until analysis. We analyzed a total of 12 barnacles from four turtles. In order to assess the consistency of recorded isotope ratios of different barnacles from a given turtle we sampled three barnacles per turtle. The barnacles were dissected and milled along their axis of growth using a Merchantek MicroMill (Electro Scientific Industries, Inc., Portland, United States) to take calcite samples. The mill was programmed to make passes on the outer facing surface of the paries perpendicular to the axis of growth in distances $0.3-0.4 \mathrm{~mm}$ apart. For each sample, a record was kept of the distance along the growth axis from barnacles' base to where each pass had been made. Samples were taken from the outermost part of the paries to exclude any calcite deposits that might have been the result of aging and thickening of the individual plates. It should be noted that nothing is known about growth rates in this species of barnacle. The calcite samples were sent to the Keck Paleoenvironmental and Environmental Stable Isotope Laboratory at the University of Kansas, where they were analyzed for oxygen $\left(\delta^{18} \mathrm{O}\right)$ and carbon $\left(\delta^{13} \mathrm{C}\right)$ stable isotope ratios. A Kiel Carbonate Device III and a Finnigan MAT253 isotope ratio mass spectrometer (Finnigan MAT, Bremen, Germany) were used to perform the laboratory analyses.

Oxygen isotope ratios in barnacle calcite can be expected to vary predictively as a function of the water's oxygen isotope ratios and temperature and can be solved for using a conversion formula (Epstein et al., 1953) with a required modification for barnacle calcite (Killingley and Newman, 1982). We reversed the formula by rearranging variables for the water's oxygen isotope ratio, which accounts for variations in salinity, and temperature to create a map of predicted barnacle oxygen isotope ratios. We used annual average sea surface temperature data from NOAA's World Ocean Database (NOAA, 2005) for the temperature variable in the equation, and published water oxygen isotope figures from 2006 (LeGrande and Schmidt, 2006) as inputs in the equation. The resulting map allowed us to put the oxygen isotope results from the barnacles into geographic context. We used this map to create an isoscape, thereby defining the largest possible area from which the isotope values measured from the calcite could have accumulated across the life of the bar- 


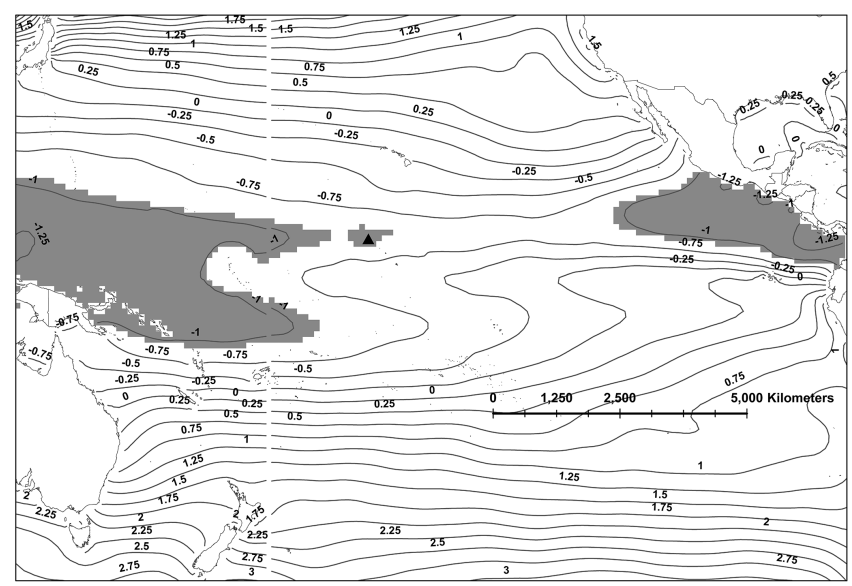

Figure 1. Oxygen isoscape (shaded in gray) showing the area in which we would expect our sea turtles to have resided throughout the life of the barnacles tested. This isoscape was calculated using an oxygen isotope ratio of $-0.951 \delta^{18} \mathrm{O}_{\mathrm{c}}$. PANWR is located within this area and depicted by the black triangle. Solid lines are contours of predicted oxygen isotope ratios in barnacle calcite $\left(\delta^{18} \mathrm{O}_{\mathrm{c}}\right)$.

nacles sampled. A detailed methodology is included as an electronic supplement.

\section{Results}

Because some of the calcite samples were not sufficiently large to be analyzed with precision in the mass spectrometer, we obtained a complete set of results for barnacles from two of the four sea turtles sampled and only partial results from one other. We included nine barnacles from three turtles in our analysis, as results from the fourth were too incomplete. The selected barnacles on the respective turtles had the following sizes measured from the base to the aperture: (i) 1.6, 1.3 and $1.6 \mathrm{~mm}$ on GD42; (ii) $1.6,2.2$, and $2.5 \mathrm{~mm}$ on GI41; and (iii) 2.0, 2.1 and $1.6 \mathrm{~mm}$ on GI43. A summary of the stable isotope ratios are reported in Table 1 . The youngest part of the barnacle is that closest to the basal margin or bottom, as the barnacle grows outward. These isotope ratios represent the values across the growth axis of the barnacle shell going from the youngest to the oldest part of the barnacle. The carbon and oxygen isotope ratios are reported versus the Vienna Pee Dee Belemnite (VPDB) scale (Coplen, 1995), which is used as a benchmark value. The maps predicting calcite oxygen isotope ratios in the central Pacific showed uniform ratios along the Equator and steep gradients towards northern and southern latitudes.

Oxygen isotope ratios in our calcite samples did not show major fluctuations throughout the life of the barnacle, while the carbon isotope ratios of the barnacles spanned 3 orders of magnitude. The highest measured oxygen isotope ratio in the collected barnacles was $-0.951 \delta^{18} \mathrm{O}$. We used this value as a contour to create an envelope in which we would expect

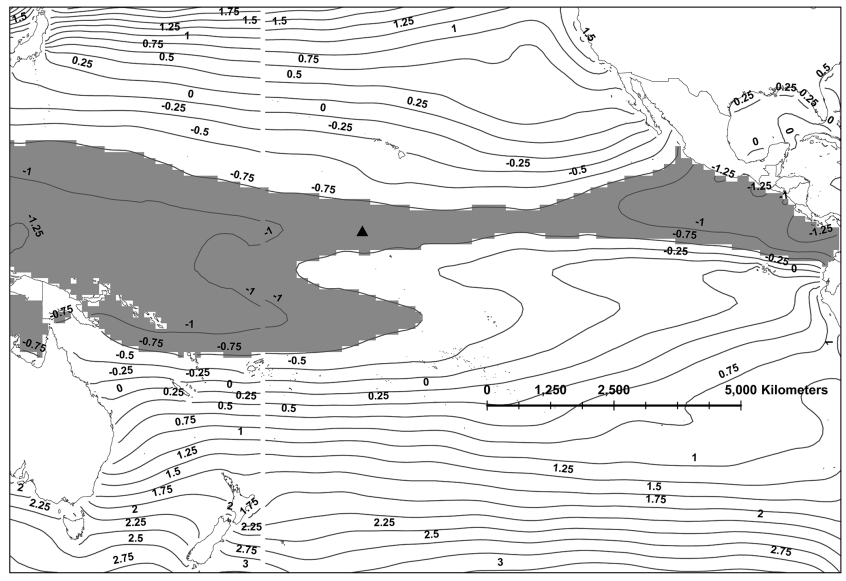

Figure 2. Adjusted oxygen isoscape (shaded in gray). PANWR is depicted by the black triangle. Solid lines are contours of predicted oxygen isotope ratios in barnacle calcite $\left(\delta^{18} \mathrm{O}_{\mathrm{c}}\right)$.

our sea turtles to have stayed throughout the lifetime of the barnacle (Fig. 1). The resulting isoscape included PANWR. We also created a more conservative isoscape that corrected for the fact that the original isoscape maps might be overestimating the isotope ratios. The first step was to identify the expected oxygen isotope ratio at PANWR on the map, as the isotopes in the barnacles' youngest layer would be expected to coincide with it. The map predicted a calcite oxygen isotope ratio of $-1.075 \delta^{18} \mathrm{O}$, while the average youngest layers of the barnacles collected were $-1.337 \delta^{18} \mathrm{O}$, giving a difference of $0.262 \delta^{18} \mathrm{O}$. Adding this difference to the original isoscape value of $-0.951 \delta^{18} \mathrm{O}$ gave a corrected calcite oxygen ratio of $-0.688 \delta^{18} \mathrm{O}$. This ratio was then used to produce a larger standardized isoscape delineating the sea turtles' movements during the barnacles' lifetime (Fig. 2).

\section{Discussion}

Our study found that oxygen isotopes in barnacles' calcite could be used to broadly delineate the area in which the sampled sea turtles moved during the life of the barnacles, allowing us to exclude visitation of major breeding grounds in the Pacific. Carbon isotopes were not informative in this study, and assessing their utility as proxies with which to explore sea turtle habitat use requires further study. Oxygen isotope values observed in the barnacles in this study indicated that the calcite ratios conform to sea temperatures of 28 and $30^{\circ} \mathrm{C}$. Assuming that average temperatures above $28^{\circ} \mathrm{C}$ are found in the warmest waters of the central Pacific that are in proximity to the Equator, our data suggest that turtles did not venture beyond these waters during the lifespan of the barnacles collected. This is consistent with observations from the field, which suggest that turtles spend extended periods of time in PANWR (Sterling et al., 2013). 
Table 1. Distance from paries' base, oxygen isotope ratio and carbon isotope ratio in Platylepas sp. barnacles collected from three green sea turtles (GD42, GI41, and GI43) in Palmyra Atoll National Wildlife Refuge. Rows show the average of three barnacles per turtle sampled. Distance is given in millimeters and isotope ratios are reported versus the VPDB scale.

\begin{tabular}{rrr|rrr|rrr}
\hline \multicolumn{3}{c|}{ Distance from base } & \multicolumn{3}{c|}{$\delta^{18}$ O concentration } & \multicolumn{3}{c}{$\delta{ }^{13}$ C concentration } \\
\hline GD42 & GI41 & GI43 & GD42 & GI41 & GI43 & GD42 & GI41 & GI43 \\
\hline 0.350 & 0.350 & 0.350 & -1.359 & -1.343 & -1.310 & 0.729 & -0.451 & -0.299 \\
0.719 & 0.727 & 0.743 & -1.283 & -1.220 & -1.431 & 0.798 & -0.398 & -0.619 \\
1.052 & 1.135 & 1.107 & -1.414 & -1.168 & -1.200 & 0.624 & -0.124 & -0.914 \\
1.403 & 1.559 & 1.451 & -1.500 & -1.097 & -1.160 & 1.090 & 0.009 & -0.481 \\
1.550 & 1.937 & 1.725 & -1.503 & -1.004 & -1.476 & 1.430 & -0.002 & 0.096 \\
n/a & 2.354 & 2.067 & n/a & -1.321 & -1.379 & n/a & 0.227 & -0.811 \\
\hline
\end{tabular}

To obtain a more concrete picture of the sea turtles' movements, we used the predicted calcite oxygen isotope map estimating the area within which the sea turtles may have moved. The contour delineating the isoscape of possible movements was large (Figs. 1 and 2) as water temperatures in the central Pacific are relatively uniform. However, some major known green turtle grounds that are within in the potential migratory range of green turtles from PANWR were not within this isoscape (STC, 2012). These include Ogasawara Island (Japan), NW Australia, and Hawaii, which also remain outside of the boundary when using the more conservative adjusted oxygen isoscape. Importantly, recent research shows that the natal origin of sea turtles in PANWR can almost exclusively be found to the west and south of the central Pacific (Naro-Maciel et al., 2014). Therefore, the boundaries we delineate in this study (1) include PANWR, (2) are consistent with ecological observation, and (3) are consistent with new genetic evidence about the population structure of green sea turtles at PANWR.

Because we cannot exclude the possibility that our isoscapes simply reflect residency at Palmyra, we are unable to quantify the method's utility as an indicator of large-scale movements. However, our data suggest that it can be used to delineate envelopes of likely residency across the Pacific basin. Therefore we suggest that this method has the potential to provide valuable data to inform comprehensive management strategies, by helping identify specific ecological and political areas within or outside a given population's range.

A wide range in the barnacles' carbon isotopes may indicate that turtles made use of a variety of microhabitats around the atoll, possibly moving between areas like the lagoon and the pelagic zone, which are assumed to have low and high carbon conditions respectively (Killingley and Lutcavage, 1983). An alternative explanation is that the turtles are frequenting ecologically heterogeneous areas beyond PANWR. However, any conclusions drawn from these results need to be viewed conservatively, as a heterogeneous environment does not necessarily explain the lack of consistency in our data, which have marked dissimilarities in carbon isotope ratios between barnacles on the same turtle. There could be dif- ferences in uptake or expression of carbon isotopes in each barnacle possibly limiting the use of the carbon isotope data in this study system. Previous studies used a larger barnacle species than the ones found on the green turtles at PANWR (Killingley and Lutcavage, 1983). Platylepas sp. specimens that we collected had sizes ranging between 1.3 and $2.5 \mathrm{~mm}$, which is a magnitude smaller than the Chelonibia testudinaria recovered from loggerhead turtles in previous studies (Killingley, 1980; Killingley and Lutcavage, 1983). This resulted in fewer data points and limited statistical analysis of the results.

In summary, this limited data set suggests that inferences about green sea turtle spatial ecology obtained from isotope analysis are broadly consistent with field observations and genetic analyses. Isotope analysis may provide lowresolution information about sea turtle connectivity, potentially defining areas of interest for research and management. Therefore, we suggest that this method can only complement but not replace other tools to investigate turtle migration and habitat use patterns. One advantage of the method is its low cost. The total cost of analyzing three barnacles on one sea turtle was below USD 170 (USD 56 per barnacle in 2011). This makes using barnacle proxies an option that could be explored further in the study of spatial ecology and could be improved in future applications.

Future research can add critical information with which to improve this method. We lack basic information about the natural history of many turtle epibionts. Because of the dearth of data on baseline growth rates for Platylepas sp., the time span between successive calcite layers is unknown, and therefore the system cannot be attached to an absolute temporal scale. We also lack benchmarks for isotope ratios in barnacles. Therefore, it is difficult to draw conclusions about the significance of fluctuations that we observed, especially for the variation in carbon isotope ratios. The utility of barnacles as proxies of sea turtle movement at study sites such as PANWR might not be fully realized until these key knowledge gaps are addressed. 


\section{The Supplement related to this article is available online at doi:10.5194/bg-12-7081-2015-supplement.}

Acknowledgements. We are very grateful to L. Ivany for advice on sample preparation and the use of milling equipment at Syracuse University. E. Lazo-Wasem provided guidance on barnacle dissection and taxonomy. AMNH field staff and the staff at PANWR provided invaluable logistical support. We would like to thank J. Drew for his revisions and input. Two anonymous reviewers provided comments that improved this manuscript. This material is based upon work supported by awards NA07NMF4540185 and NA10NMF4540299 from the National Oceanic and Atmospheric Administration's National Marine Fisheries Service, US Department of Commerce, and a Lerner-Gray Marine Research grant from the American Museum of Natural History. The statements, findings, conclusions, and recommendations are those of the author(s) and do not necessarily reflect the views of the National Oceanic and Atmospheric Administration or the US Department of Commerce. We acknowledge the Palmyra Atoll National Wildlife Refuge, US Fish and Wildlife Service, Department of the Interior. This is Palmyra Atoll Research Consortium publication number PARC-0119.

Edited by: S. W. A. Naqvi

\section{References}

Bowen, B. W. and Karl, S. A.: Population genetics and phylogeography of sea turtles, Mol. Ecol., 16, 4886-4907, 2007.

Byers, J. E., Altman, I., Grosse, A. M., Huspeni, T. C., and Maerz, J. C.: Using parasitic trematode larvae to quantify an elusive vertebrate host, Conserv. Biol., 25, 85-93, 2011.

Casale, P., Freggi, D., Basso, R., and Argano, R.: Epibiotic barnacles and crabs as indicators of Caretta caretta distribution and movements in the Mediterranean Sea, J. Mar. Biol. Assoc. UK, 84, 1005-1006, 2004.

Collen, J. D., Garton, D. W., and Gardner, J. P. A.: Shoreline changes and sediment redistribution at Palmyra Atoll (Equatorial Pacific Ocean): 1874-Present, J. Coast. Res., 25, 711-722, 2009.

Coplen, T.: Reporting of stable hydrogen, carbon, and oxygen isotopic abundances, Geothermics, 24, 707-712, 1995.

Epstein, S., Buchsbaum, R., Lowenstam, H. A., and Urey, H. C.: Revised carbonate-water isotopic temperature scale, Geol. Soc. Am. Bull., 64, 1315-1326, 1953.

Frick, M. G., Zardus, J. D., and Lazo-Wasem, E. A.: A new Stomatolepas barnacle species (Cirripedia: Balanomorpha: Coronuloidea) from leatherback sea turtles, Bulletin of the Peabody Museum of Natural History, 51, 123-136, 2010.

Godley, B. J., Barbosa, C., Bruford, M., Broderick, A. C., Catry, P., Coyne, M. S., Formia, A., Hays, G. C., and Witt, M. J.: Unravelling migratory connectivity in marine turtles using multiple methods, J. Appl. Ecol., 47, 769-778, 2010.

Hays, G. C., Bradshaw, C. J. A., James, M. C., Lovell, P., and Sims, D. W.: Why do Argos satellite tags deployed on marine ani- mals stop transmitting?, J. Experim. Mar. Biol. Ecol., 349, 5260, 2007.

Hebblewhite, M. and Haydon, D. T.: Distinguishing technology from biology: a critical review of the use of GPS telemetry data in ecology, Philosoph. Trans. Roy. Soc. B, 365, 2303-2312, 2010.

Hechinger, R. F., Lafferty, K. D., Huspeni, T. C., Brooks, A. J., and Kuris, A. M.: Can parasites be indicators of free-living diversity? Relationships between species richness and the abundance of larval trematodes and of local benthos and fishes, Oecologia, 151, 82-92, 2007.

Kendall, C. and Caldwell, E. A.: Fundamentals of isotope geochemistry, Isotope tracers in catchment hydrology, Fundamentals of isotope geochemistry Book, in: Isotope tracers in catchment hydrology, 51-86, 1998.

Killingley, J. and Newman, W.: ${ }^{18} \mathrm{O}$ fractionation in barnacle calcite: a barnacle paleotemperature equation, J. Mar. Res., 40, 893 902, 1982.

Killingley, J. S.: Migrations of California gray whales tracked by Oxygen-18 variations in their epizoic barnacles, Science, 207, 759-760, 1980.

Killingley, J. S. and Lutcavage, M.: Loggerhead turtle movements reconstructed from ${ }^{18} \mathrm{O}$ and ${ }^{13} \mathrm{C}$ profiles from commensal barnacle shells, Estuarine, Coast. Shelf Sci., 16, 345-349, 1983.

LeGrande, A. N. and Schmidt, G. A.: Global gridded data set of the oxygen isotopic composition in seawater, Geophys. Res. Lett., 33, L12604, doi:10.1029/2006GL026011, 2006.

McFadden, K. W., Gómez, A., Sterling, E. J., and Naro-Maciel, E.: Potential impacts of historical disturbance on green turtle health in the unique \& protected marine ecosystem of Palmyra Atoll (Central Pacific), Mar. Pollut. Bull., 89, 160-167, 2014.

Naro-Maciel, E., Gaughran, S. J., Putman, N. F., Amato, G., Arengo, F., Dutton, P. H., McFadden, K. W., Vintinner, E. C., and Sterling, E. J.: Predicting connectivity of green turtles at Palmyra Atoll, central Pacific: a focus on mtDNA and dispersal modelling, J. Roy. Soc. Inter., 11, 20130888, doi:10.1098/rsif.2013.0888, 2014.

Nieberding, C. M. and Olivieri, I.: Parasites: proxies for host genealogy and ecology?, Trends Ecol. Evolut., 22, 156-165, 2007.

NOAA: http://www.nodc.noaa.gov/OC5/indprod.html last access: 4 March 2012

Oosthuizen, W. C., De Bruyn, P., Bester, M. N., and Girondot, M.: Cohort and tag-site-specific tag-loss rates in mark-recapture studies: A southern elephant seal cautionary case, Mar. Mamm. Sci., 26, 350-369, 2010.

Rawson, P. D., Macnamee, R., Frick, M. G., and Williams, K. L.: Phylogeography of the coronulid barnacle, Chelonibia testudinaria, from loggerhead sea turtles, Caretta caretta, Mol. Ecol., 12, 2697-2706, 2003.

Schwartz, F.: The barnacle Platylepas hexastylos encrusting a green turtle, Chelonia mydas mydas, from Chincoteague Bay, Maryland, Chesapeake Science, 1, 116-117, 1960.

STC: http://www.conserveturtles.org/seaturtlenestingmap.php, last access: 15 May 2012.

Sterling, E. J., McFadden, K., Holmes, K., Vintinner, E., Arengo, F., and Naro-Maciel, E.: Ecology and conservation of marine turtles in a foraging ground in the Central Pacific, Chelonian Conserv. Bi., 12, 2-16, 2013.

Torres-Pratts, H., Scharer, M. T., and Schizas, N. V.: Genetic diversity of Chelonibia caretta, commensal barnacles of the en- 
dangered hawksbill sea turtle Eretmochelys imbricata from the Caribbean (Puerto Rico), J. Mar. Biol. Assoc. UK, 89, 719-725, 2009.

Wallace, B. P., DiMatteo, A. D., Hurley, B. J., Finkbeiner, E. M., Bolten, A. B., Chaloupka, M. Y., Hutchinson, B. J., AbreuGrobois, F. A., Amorocho, D., Bjorndal, K. A., Bourjea, J., Bowen, B. W., Duenas, R. B., Casale, P., Choudhury, B. C., Costa, A., Dutton, P. H., Fallabrino, A., Girard, A., Girondot, M., Godfrey, M. H., Hamann, M., Lopez-Mendilaharsu, M., Marcovaldi, M. A., Mortimer, J. A., Musick, J. A., Nel, R., Pilcher, N. J., Seminoff, J. A., Troeng, S., Witherington, B., and Mast, R. B.: Regional Management Units for Marine Turtles: A novel framework for prioritizing conservation and research across multiple scales, PLoS One, 5, e15465, doi:10.1371/journal.pone.0015465, 2010.
Zardus, J. D. and Balazs, G. H.: Two previously unreported barnacles commensal with the green sea turtle, Chelonia mydas (Linnaeus, 1758), in Hawaii and a comparison of their attachment modes, Crustaceana, 80, 1303-1315, 2007. 